\title{
Os “covidismos" em português e em polaco
}

\section{COVID Words in Portuguese and Polish}

PrzemysŁaw DęBowiak [przemyslaw.debowiak@uj.edu.pl]

Uniwersytet Jagielloński w Krakowie, Polónia

\section{RESUMO}

Desde março de 2020, mês em que a pandemia da covid-19 se alastrou a nível global, têm surgido numerosos vocábulos em várias línguas. O objetivo deste trabalho é apresentar e analisar os neologismos formados com base no termo covid, usados em português e em polaco para referir diferentes aspetos da realidade pandémica. Analisam-se 22 itens portugueses e 25 itens polacos. As palavras recolhidas são estudadas do ponto de vista formal e semântico numa perspetiva comparativa, apontando-se para as semelhanças e diferenças entre os "covidismos" em ambas as línguas.

\section{Palavras-chave}

Covid-19; neologismo; empréstimo; português; polaco

\begin{abstract}
From March 2020 on, month in which the COVID-19 pandemic spread on a global scale, numerous words in various languages have arisen. The purpose of this work is to present and analyze neologisms formed on the basis of the term COVID, used in Portuguese and Polish to refer to different aspects of the pandemic reality. 22 Portuguese and 25 Polish items are analyzed. Collected words are studied from the formal and semantic point of view in a comparative perspective. Similarities and differences between the COVID words in both languages are pointed out.
\end{abstract}

\section{KEYWORDS}

COVID-19; neologism; borrowing; Portuguese; Polish

RECEBIDO 2021-03-16; ACEITE 2021-03-29 
Desta infinita chatice,

deste tempo malfazejo,

sobrará a covidice

de me negares um beijo.

(Caminha 2020)

\section{Introdução}

O léxico constitui o domínio aberto da língua que mais dinamicamente reage e se adapta à realidade extralinguística em constante evolução, sendo, muitas vezes, um espelho dos acontecimentos que constroem passo a passo a história da humanidade. Em termos de língua, essa história reflete-se, por um lado, nos neologismos, que surgem em várias ocasiões, e, por outro lado, nas unidades lexicais que se vão tornando obsoletas e, passando por uma etapa de arcaísmos, acabam por cair em esquecimento. Nos últimos anos, fosse no seio de comunidades monolingues ou entre falantes de várias línguas, a circulação de novas palavras tem vindo a intensificar-se, um processo propiciado pela internet, sobretudo através das redes sociais, e pelos mass media. No âmbito de uma determinada língua, os neologismos tanto podem ser criações internas, como itens lexicais importados de fora, hoje em dia particularmente do inglês.

A pandemia da doença covid-19, causada pela propagação acelerada de uma nova estirpe de coronavírus, é um exemplo modelo de uma situação em que as mudanças, nunca antes testemunhadas pela comunidade mundial, são tão rápidas e radicais que deixam imediatamente muitas pegadas na língua. Isso resulta da necessidade de exprimir e nomear elementos da realidade que, neste caso em particular, repentina e forçadamente, se tornaram importantes na vida quotidiana do ser humano. Assim, a partir de finais de 2019, quando o novo coronavírus foi identificado na China e os olhos do mundo se viraram atentamente para a situação nesse país, várias línguas viram multiplicar a frequência do uso de certas palavras (p.ex. contágio, epidemia, pandemia, máscara, confinamento, distanciamento, quarentena...), enquanto outras foram nascendo. Nos idiomas falados na Europa, esse processo tem vindo a acelerar especialmente desde março de 2020, mês em que a pandemia eclodiu no nosso continente ${ }^{1}$.

De facto, a própria palavra coronavírus já existia em várias línguas como um termo genérico antes dos acontecimentos acabados de referir. Originalmente, os coronavírus são um tipo de vírus que devem o seu nome à forma que têm, parecendo-se com uma coroa solar na parte exterior (do latim corōna 'coroa'). Nos últimos tempos, tem-se usado essa designação no mundo inteiro com um significado limitado a um só coronavírus, nomeadamente, o SARS-CoV-2 (do inglês severe acute respiratory syndrome coronavirus 2 'coronavírus relacionado com a síndrome respiratória aguda grave 2'), que é o patógeno da doença chamada covid-19 (cf. abaixo). Mesmo assim, fora dos meios restritos de virologistas, o termo coronavírus é uma aquisição lexical recente, à qual vieram juntar-se logo outros vocábulos e expressões, formando uma espécie de gíria da pandemia. Alguns elementos desse jargão são comuns a várias línguas e deixam-

1 Os primeiros casos de covid-19 foram oficialmente detetados em 2 de março em Portugal e em 4 de março de 2020 na Polónia. Quanto aos outros países lusófonos, as datas homólogas são as seguintes: Brasil: 26 de fevereiro; Cabo Verde: 20 de março; Angola: 21 de março; Timor-Leste: 21 de março; Moçambique: 22 de março; Guiné-Bissau: 25 de março; São Tomé e Príncipe: 6 de abril. 
se compreender a nível internacional, ao passo que outros, numa perspetiva global, funcionam como regionalismos.

Essas mudanças lexicais dinâmicas não passaram despercebidas a linguistas, jornalistas, políticos e utilizadores comuns de língua. Não se fizeram esperar artigos, comentários, crónicas, listas de palavras, entrevistas, dúvidas, piadas e outros tipos de textos sobre os tecnicismos e neologismos da pandemia do coronavírus, colocados livremente na internet. Desde março de 2020 que essa temática tem sido abordada e desenvolvida em vários países e línguas. A título de exemplo, o governo do Canadá deu a conhecer um glossário bilingue (em inglês e francês) em março², e o Oxford English Dictionary apresentou uma lista de novas entradas em abril ${ }^{3}$. No mesmo site, nos primeiros meses da pandemia, publicaram-se alguns artigos sobre a linguagem da covid-19 (OED1; Salazar 2020; OED2). Em julho, foi divulgado no Luxemburgo um glossário multilingue do léxico relacionado com a pandemia (LOD), anunciado também na imprensa lusófona do país ${ }^{4}$. Exemplos de textos parecidos que saíram em 2020 poder-se-iam multiplicar (cf. p.ex. Marin La Meslée 2020; Moran 2020; Ro 2020; Lasalle 2020); também não tardaram artigos em revistas científicas (p.ex. Belhaj 2020; Roig-Marín 2020).

Em várias páginas da internet lusófona apareceram igualmente diferentes tipos de textos que abordam essa problemática (p.ex. Três Pontos 2020; Vidente Luemba 2020; Alvarez 2020; Martingo 2020; Gaglioni 2020; Soares 2020; Ribeiro Ferreira 2020; Marques 2020; Leiser Baronas, Oliveira Carreon, Fernandes dos Santos Silva 2020; Melo de Sousa, Santos Junior, Queiroz de Lima 2020). Merecem particular destaque dois glossários, nomeadamente:

- o Lexicovid-19, um dicionário temático de expressões e termos relacionados com a pandemia, de caráter enciclopédico e técnico, criado por um grupo de investigadores brasileiros (https:// www.lexicovid19.com.br/);

- O léxico da covid-19, glossário publicado no site português Ciberdúvidas da Língua Portuguesa (CDLP), iniciado em 27 de março de 2020 e desde então constantemente ampliado, exibindo centenas de palavras e expressões relacionadas com a pandemia, inclusive numerosos neologismos (https://ciberduvidas.iscte-iul.pt/lexico-covid-19/). Como escreveram recentemente (em 2 de fevereiro de 2021) os próprios editores da página em questão,

O glossário O léxico da covid-19 tem um triplo e exclusivo objetivo: 1) O registo lexical dos termos e expressões (neologismos e, até, mero jargão, inclusive) marcantes deste período da pandemia do novo coronavírus, com os respetivos significados e contextos, com a particular atenção àqueles que se revelam mais densos ou mais afastados dos conhecimentos do falante comum de português, e sempre com a devida remissão a fontes científicas (caso dos termos médicos) e autorais (v.g., frases de organismos e autoridades sanitárias e governamentais). 2) A contribuição, em simultâneo, para

2 A primeira versão do glossário foi publicada em 13 de março, e a versão atual resulta de uma modificação efetuada em 11 de junho de 2020: https://www.btb.termiumplus.gc.ca/publications/covid19-eng.html, https://www.btb. termiumplus.gc.ca/publications/covid19-fra.html.

3 https://public.oed.com/updates/new-words-list-april-2020/\#.

4 Trata-se do artigo intitulado Há uma nova palavra no glossário da pandemia: "covidiota", publicado no serviço de informações luxemburguês Contacto: https://www.wort.lu/pt/sociedade/h-uma-nova-palavra-no-gloss-rio-da-pandemiacovidiota-5f2018ffda2cc1784e3629a9. 
“memória futura”, desta nova realidade vocabular na língua portuguesa. 3) A criação de um corpus alargado do léxico especificamente relacionado com as várias áreas da pandemia, com vista a possibilitar futuras reflexões e/ou investigações linguísticas. ${ }^{5}$

Em diferentes páginas da internet polaca também houve reações imediatas à realidade da pandemia e desde março de 2020 têm-se publicado numerosos textos de vários tipos (p.ex. Bloch 2020; Gawina 2020; Zdziebłowski 2020; Cierpich-Kozieł 2020; Gębka-Wolak 2020; Kuligowska 2020).

Perante um alargamento notável do léxico relacionado com a pandemia, achámos interessante analisar mais de perto esse fenómeno numa perspetiva comparativa, a saber, em duas línguas: o português e o polaco. Como o material de pesquisa é enorme, optámos por restringir o nosso estudo às palavras formadas com base no vocábulo covid. Este vem do nome da doença respiratória causada pelo coronavírus SARS-CoV-19, nomeadamente, a covid-19. A designação da enfermidade provém da sigla COVID-19 que, por sua vez, se origina em inglês: Coronavirus disease 2019 'doença por coronavírus 2019’ (identificada pela primeira vez em 2019). Em português, a palavra em causa adotou o género feminino (lembrando o do substantivo doença) e pode-se escrever tanto com maiúsculas, enquanto acrónimo, como minúsculas, enquanto nome comum, o que resulta da generalização do seu uso (CDLP s.v. COVID-19 / Covid-19; Infopédia s.v. COVID-19, covid-19; DPLP s.v. COVID-19; Dicio s.v. covid-19) ${ }^{6}$. Em polaco, a palavra covid adquiriu o género masculino por terminar em consoante e também se pode escrever com maiúsculas ou minúsculas, admitindo-se neste segundo caso igualmente a grafia polonizada kowid (WSJP s.v. COVID-19, s.v. covid; WikiPL s.v. COVID-19).

\section{Apresentação e análise dos termos recolhidos}

As fontes que nos inspiraram e levaram a criar o nosso corpus são principalmente:

- o glossário O léxico da covid-19, mencionado acima, juntando algumas centenas de entradas, publicado na página Ciberdúvidas da Língua Portuguesa (CDLP), constantemente em atualização (embora a data da publicação, 27 de março de 2020, não o indique), e nas subpáginas correspondentes às letras particulares (aqui recorremos às letras: A, C e D);

- o artigo Vamos lá falar em... Covidês. As palavras que a pandemia colocou na nossa boca que exibe cerca de 30 palavras e expressões relacionadas com a pandemia, publicado na revista Visão em maio de 2020 (Soares 2020);

- a página Najnowsze Słownictwo Polskie que regista e analisa o léxico mais recente da língua polaca, com mais de 8500 entradas, fazendo parte do Observatório Linguístico da Universidade de Varsóvia (NSP).

5 https://ciberduvidas.iscte-iul.pt/artigos/rubricas/controversias/testar-ou-nao-testar-eis-a-questao/4388.

6 O vocábulo covid tem tido tanto sucesso que até conseguiu providenciar notoriedade a uma aldeia portuguesa situada na parte setentrional do país, chamada Covide (Timóteo 2020). 
O corpus foi sendo ampliado através da consulta de várias páginas web, tendo as pesquisas sido efetuadas no motor de busca Google. ${ }^{7}$

Cada termo encontrado é apresentado de acordo com o seguinte esquema: forma(s), informação gramatical, etimologia, significado(s), ocorrência nas fontes e em dicionários eletrónicos atualizados continuamente (Infopédia, DPLP, WikiPT, Aulete e Dicio para o português, WSJP, $\mathrm{SJP}^{8}$ e WikiPL para o polaco) ${ }^{9}$, exemplo(s) de uso (frases tiradas de textos publicados na internet). $\mathrm{O}$ estudo divide-se em dois grupos, segundo a língua (2.1. português, 2.2. polaco), e os vocábulos estão apresentados em ordem alfabética. Omitem-se as palavras ocasionais que no momento da pesquisa ocorriam apenas num texto ou no idioleto de uma só pessoa.

\subsection{Português}

As unidades lexicais portuguesas que recolhemos são as seguintes:

- anticovid, anticovid-19, adj. (derivado prefixal de covid, covid-19, cf. inglês anti-COVID, antiCOVID-19), 'destinado a combater ou proteger contra a covid-19' (CDLP s.v. anticovid; DPLP s.v. anticovid); ex.: "O Governo admite "disponibilidade total" para rever as medidas anticovid-19." ${ }^{\prime \prime}$;

- covid, covid-19, adj. (derivação imprópria de covid, s.f.), 'relativo à covid-19; com covid-19; causado pela covid-19' (CDLP s.v. doente (não) covid); ex.: "O Hospital de Braga contava hoje com 119 doentes covid-19 internados em enfermaria e 33 em cuidados intensivos."

- covid-drive, s.m. (do inglês COVID drive-thru / COVID drive-through), 'centro de testes à covid-19 em que o utente é testado sem ter de sair do seu automóvel' ( $\left.\varnothing^{12}\right)$; ex.: “Barcelos vai reabrir o "covid-drive"'"13;

7 Como no tempo da redação do presente estudo (primeira metade de fevereiro de 2021) a pandemia da covid-19 ainda está para durar e a moldar profundamente a realidade, inclusive a língua, é possível que dentro de alguns meses o nosso corpus esteja longe de ser exaustivo. Como as mudanças linguísticas que temos testemunhado nos últimos doze meses são bastante dinâmicas, nada impede, e até se espera, que apareçam mais neologismos no período entre a entrega da versão final do texto aos editores da revista e a publicação do volume.

8 De facto, alguns termos registam-se não no próprio dicionário, mas sim na lista de palavras submetidas à edição de 2020 do concurso A Palavra do Ano dos Adolescentes (pol. Młodzieżowe Słowo Roku) e para a qual remete o motor de busca da página inicial do dicionário.

9 Verificámos a presença da totalidade dos vocábulos portugueses e polacos em todos os dicionários enumerados. No entanto, na apresentação só exibimos as fontes em que o vocábulo em questão aparece e omitimos as outras; caso não apareça em nenhuma fonte, assinalamo-lo com o símbolo “ø”. Observe-se já que os dicionários WikiPT, Aulete e Dicio não registam nenhuma das unidades lexicais que aqui se analisam.

10 https://www.publico.pt/2020/10/08/sociedade/noticia/mascara-ar-livre-testes-rapidos-semaforo-combatecovid19-passar-aqui-1934447.

11 https://www.cmjornal.pt/sociedade/detalhe/hospital-de-braga-recebeu-primeiro-doente-covid-do-amadorasintra.

12 No entanto, o site Ciberdúvidas da Língua Portuguesa nota o mesmo conceito sob o nome Drive Thru: https:// ciberduvidas.iscte-iul.pt/artigos/rubricas/idioma/o-lexico-da-covid-19/4138.

13 https://www.jn.pt/local/noticias/braga/barcelos/barcelos-volta-a-ter-o-covid-drive--12995094.html. 
- covidade desportiva, s.f. (derivado sufixal de covid, talvez com base em modalidade desporti$v a$ ), 'disseminação da covid-19 no meio dos desportistas que afeta o rendimento das equipas' (CDLP s.v. "covidade" desportiva); ex.: "Como fica a 'covidade' desportiva?"14;

- covidar, vintr. (derivação imprópria de covid, s.f., talvez com base em convidar e/ou conversar), 'ter momentos de convívio com outras pessoas, à distância ou não, na época da pandemia da covid-19' (CBLP s.v.; Soares 2020); ex.: "Sabe a última? A nova "moda” jovem? Chama-se covid-amos! Covid-amos para uma "nite", uma "rave”, umas "bejecas" em qualquer sítio."15;

- covidário, s.m. (derivado sufixal de covid), 'espaço hospitalar onde se recebem e tratam doentes suspeitos ou portadores do coronavírus' (CDLP s.v.; Soares 2020; Infopédia s.v.; DPLP s.v.); ex.: "O covidário do Hospital Dr. Nélio Mendonça atingiu a sua lotação máxima."16;

- covidelírio, s.m. (hibridismo: covid + delírio), ‘delírio causado pela pandemia da covid-19’ (ø); ex.: “Também a população padece de covidelírio, pois sofre de uma distorção aguda da realidade que a faz ouvir vozes que lhe sussurram para deixar a cautela de lado junto às máscaras e se unir à multidão." (Einstein-Schweriner 2021);

- covidês, s.m. (derivado sufixal de covid), 'linguagem particular, especificamente em termos de vocabulário, usada para descrever a realidade da pandemia da covid-19' (CDLP s.v.; Soares 2020); ex.: "Em tempos de pandemia instituiu-se um novo dialecto - o covidês - que de certa forma veio ocupar o lugar do futebolês." 17 ;

- Covidexit, s.m. (do inglês Covid-exit / Covid exit, com base no termo Brexit 'saída do Reino Unido da União Europeia'), 'saída das restrições do período da pandemia da covid-19' (CDLP s.v.; Soares 2020); ex.: "Do porquê de fazer um GAP Year Académico em Inglaterra em tempos de Covidexit" ${ }^{\prime 18}$;

- covidiano, adj. (derivado sufixal de covid, cf. inglês Covidian, francês covidien), 'relativo à covid-19” (Infopédia s.v.; DPLP s.v.); ex.: “Cuidado, primeiro-ministro, com esta máquina covidiana arriscamo-nos a ter de devolver metade dos fundos resilientes!"19;

- covidice, s.f. (derivado sufixal de covid), 'aquilo que se faz na época pandemia da covid-19 e que nunca se tinha feito antes' (CDLP s.v. $\left.{ }^{20}\right)$; ex.: "Seja como for, esta "covidice" veio atrapalhar um pouco a lenda criada em torno do Hamilton."

- covídico, adj. (derivado sufixal de covid), 'relativo à covid-19' (CDLP s.v. covidário; Infopédia s.v.; DPLP s.v.); ex.: "Agências e marcas têm de ser reinventar para enfrentar o inverno covídico."22;

$14 \mathrm{https} / /$ www.record.pt/opiniao/cronistas/vitor-pinto/detalhe/como-fica-a-covidade-desportiva?ref=V\%C3\%ADtor\%20 Pinto_DestaquesPrincipais.

15 https://enquantoalmocamos.blogspot.com/2020/07/a-covidice.html. Note-se que a forma covidar ocorre nos resultados da busca no Google, mas na maior parte dos casos, graças ao contexto, está claro que ela resulta de uma gralha, tendo os autores pretendido, de facto, usar o verbo transitivo convidar.

16 https://www.dnoticias.pt/2020/12/17/243192-esta-lotado-o-covidario-do-hospital-dr-nelio-mendonca/.

17 https://maisguimaraes.pt/o-regresso-a-normalidade/.

18 https://yourwayeducation.pt/artigos/este-e-o-melhor-ano-para-fazer-um-gap-academico-no-reino-unido-e-hora.

19 https://www.jornaldenegocios.pt/opiniao/colunistas/luis-nazare/detalhe/a-maquina-covidiana.

20 Soares (2020) regista o termo covidice, mas numa aceção que não conseguimos confirmar na nossa pesquisa. Cf. abaixo.

21 https://blogvisaodemercado.pt/2020/12/vitoria-sergio-perez-na-f1/.

22 https://www.dn.pt/dinheiro/na-era-do-covid-19-as-marcas-tem-de-ser-esquimos-da-comunicacao-12013562.html. 
- covidioma, s.m. (hibridismo: covid + idioma, cf. espanhol covidioma), 'linguagem particular, especificamente em termos de vocabulário, usada para descrever a realidade da pandemia da covid-19' (Araújo Pereira 2020²3); ex.: “Durante este último ano, sofremos um processo de habituação, a nível social e emocional, não só introduzimos o covidioma no nosso vocabulário, como criamos uma redoma à nossa volta que faz com que certas notícias sejam encaradas com indiferença." ${ }^{24}$;

- covidiota, s.m./f., adj. (hibridismo: covid + idiota, cf. inglês, francês covidiot, espanhol, italiano covidiota), 1) '(pessoa) que nega a existência ou menospreza a gravidade da covid-19, desrespeita as recomendações do distanciamento social e outras medidas de segurança, aumentando o risco de contágio', 2) '(pessoa) que sobrevaloriza a gravidade da covid-19 e preocupa-se com a pandemia de forma exagerada, tomando medidas desnecessárias, como estocar papel higiénico’ (CDLP s.v. (só na 1.a aceção); Soares 2020 (só na 1. aceção); LOD s.v. Covidiot); ex.: 1) "Pior, muito pior: os covidiotas e os antivacinas vão aproveitar a desconfiança naquela vacina para porem as pessoas a desconfiar também de todas as outras." ${ }^{25}$; 2) "Esse cidadão histérico, amedrontado e alarmista tornou-se conhecido como covidiota." ${ }^{26}$;

- covidismo, s.m. (derivado sufixal de covid, cf. inglês Covidism, francês covidisme), 1) 'palavra ou expressão típica da linguagem usada para descrever a realidade da pandemia da covid-19', 2) 'atitude de quem sobrevaloriza a gravidade da covid-19' (Zimmer 2021 (só na 1. aceção) ${ }^{27}$ ); ex.: 1) "Neste sentido, é nossa missão apresentar, com todo o cuidado possível, alguns "covidismos", ou seja, palavras já dicionarizadas (muitas delas adormecidas ou desconhecidas por alguns falantes) e novas, em vias de lexicalização, que, por força da covid-19, ganharam maior uso, tornando-se palavras/expressões da actualidade, palavras recorrentes da Covid-19." (Vidente Luemba 2020: 18); 2) "Entre os inimigos a serem enfrentados, o chanceler aponta "a grande mídia”, a "bandidagem" e até o "covidismo"'”28;

- covidista, s.m./f., adj. (derivado sufixal de covid, cf. inglês Covidist), '(pessoa) que sobrevaloriza a gravidade da covid-19 e preocupa-se com a pandemia de forma exagerada, tomando medidas desnecessárias, como estocar papel higiénico' (Zimmer 202129); ex.: "Nas tais caricaturas simplistas, os negacionistas ignoram e descuram, confundindo liberdade individual com incúria e desprezo pelos outros, e os covidistas sobrevalorizam a doença em detrimento de tudo o resto, convertendo-se alegremente em bufos higienistas,

23 De facto, o site Ciberdúvidas da Língua Portuguesa regista o vocábulo covidioma através da reedição da mesma crónica: https://ciberduvidas.iscte-iul.pt/artigos/rubricas/idioma/o-covidioma/4274.

24 https://www.juponline.pt/opiniao/artigo/37701/confinamento-medidas-tenues-populacao-anestesiada.aspx.

25 https://jornaldocentro.pt/opiniao/serendipidade.

26 https://rothbardbrasil.com/o-culto-dos-covidiotas-e-a-seita-politica-do-medo-escatologico/.

27 De facto, este artigo constitui uma subpágina do site Ciberdúvidas da Língua Portuguesa.

28 https://noticias.uol.com.br/internacional/ultimas-noticias/2020/12/31/em-artigo-sobre-2021-chanceler-apontamidia-e-covidismo-como-inimigos.htm.

29 De facto, este artigo constitui uma subpágina do site Ciberdúvidas da Língua Portuguesa. O termo covidista surge nele na 1. aceção de covidiota (ou seja, designa uma pessoa que não respeita as regras da quarentena, do distanciamento social, etc.), traduzindo assim o termo original inglês Covidian. Contudo, não encontrámos atestações deste significado de covidista na internet. Talvez se trate de hápax. 
partidários de comportamentos ditatoriais do seu próprio Estado de validade científica duvidosa, com inusitada fé nas boas intenções do mesmo." ${ }^{30}$;

- covidivórcio, s.m. (hibridismo: covid + divórcio, cf. inglês covidivorce, espanhol covidivorcio), 'separação conjugal resultante do confinamento em casa imposto por causa da pandemia da covid-19' (CDLP s.v.; Soares 2020); ex.: "Em tempos de covidivórcio, apelido dado a onda de separações provocado pelo confinamento do Covid-19, estar solteiro pode até parecer uma benção." ${ }^{31}$;

- covidmaníaco, s.m., adj. (composto morfológico ${ }^{32}$ de covid + maníaco, cf. inglês Covid maniac, italiano covid-maniaco), '(pessoa) que tem obsessão pela covid-19, que sobrevaloriza a gravidade da covid-19 e preocupa-se com a pandemia de forma exagerada' (ø); ex.: "Os covidmaníacos são pessoas que vivem com tanto medo da COVID-19 que simplesmente praticamente deixam de viver." 33 ;

- Covidolândia, s.f. (composto morfológico de covid e -lândia, cf. inglês Covidland), 'terra em que se registam muitos casos de covid-19' (ø); ex.: "Covidmaníacos e Covidiotas: uma aventura na Covidolândia" 34 ;

- não-covid / não covid, não-covid-19 / não covid-19, adj. (derivado prefixal de covid, covid-19 adj., cf. inglês non-COVID), 'que não é relativo à covid-19; não causado pela covid-19' (CDLP s.v. doente (não) covid); ex.: "O candidato presidencial Tiago Mayan Gonçalves mostrou-se esta sexta-feira preocupado com a resposta aos problemas de saúde não covid-19 e com as cirurgias e diagnósticos que estão a ser deixados para trás." ${ }^{35}$;

- pós-covid, pós-covid-19, s.m., adj. (derivado prefixal de covid, cf. inglês post-Covid), '(relativo à) realidade posterior à pandemia da covid-19' (CDLP s.v.); ex.: "A coragem destas horas não se joga apenas na primeira frente de combate à pandemia, mas também na resiliência e ousadia necessárias para pensar no que seremos no pós-covid-19." 36 ;

- pré-covid, pré-covid-19, s.m., adj. (derivado prefixal de covid, cf. inglês pre-Covid), '(relativo à) realidade anterior à pandemia da covid-19' (CDLP s.v.); ex.: “2021 traz recuperação às empresas mas não ainda para níveis pré-covid" ${ }^{37}$.

Convém acrescentar que algumas das palavras enumeradas não têm significado fixo. Assim, Soares (2020) define covidice como 'teoria da conspiração e/ou outro conteúdo viral deste género, partilhado nos comunicadores instantâneos'. Por sua vez, o site Três Pontos (2020) define covidelírio como 'pensamento causado pelo confinamento obrigatório'. Para além disso, na internet

30 https://observador.pt/opiniao/negacionistas-versus-covidistas/.

31 https://heloisatolipan.com.br/gente/artistas-falam-sobre-o-oi-sumida-o-e-ate-onde-vai-a-paquera-virtual-nessemomento-de-pandemia/.

32 Termo usado conforme Villalva (2003: 972-978) para designar uma palavra que resulta da concatenação de radicais.

33 https://ursotobias.blogs.sapo.pt/alucinados-da-covid-19-237266.

34 https://reportersombra.com/covidmaniacos-e-covidiotas-uma-aventura-na-covidolandia/.

35 https://tvi24.iol.pt/politica/sns/tiago-mayan-preocupado-com-resposta-a-doentes-nao-covid-19.

36 https://expresso.pt/opiniao/2020-04-18-10-perguntas-para-o-pos-covid-19.

37 https://www.jornaldenegocios.pt/empresas/detalhe/2021-traz-recuperacao-as-empresas-mas-nao-ainda-paraniveis-pre-covid. 
podem encontrar-se mais neologismos baseados em covid: covinado '(alguém que está) confinado em casa' (Três Pontos 2020), esquizocovidfrenia 'epidemia de um transtorno psíquico parecido com a esquizofrenia, causada pela pandemia da covid-19' (Einstein-Schweriner 2021). Contudo, como não encontrámos nenhumas atestações desses termos e aceções fora dos sites em questão, achámos tratar-se de hápax e não os incluímos na análise.

\subsection{Polaco}

Seguem-se os itens polacos que conseguimos encontrar:

- antycovidowiec / antykowidowiec, s.m. (derivado sufixal de antycovidowy / antykowidowy), 'pessoa que nega a existência ou menospreza a gravidade da covid-19' (WikiPL s.v. antymaseczkowiec, s.v. covidiota, s.v. koronasceptyk); ex.: "Były poseł antycovidowiec w szpitalu z koronawirusem" 38 ;

- antycovidowy / antykowidowy, adj. (derivado prefixal de covidowy / kowidowy, cf. inglês antiCOVID, anti-COVID-19), 1) 'destinado a combater ou proteger contra a covid-19; anticovid', 2) 'que nega a existência ou menospreza a gravidade da covid-19' (ø); ex.: 1) 'Zamów pakiety antycovidowe niezbędne w każdym biurze!"39, 2) "Antycovidowy marsz w Katowicach"40;

- bezcovidowy / bezkowidowy, adj. (derivado prefixal de covidowy / kowidowy), 'que não tem covid-19, em que não há covid-19’ (ø); ex.: “Zobaczysz ty rok bezkowidowy tak samo szybko jak Legię zdobywającą mistrzostwo bez żadnych przekrętów, czyli nie w tym wieku." ${ }^{41}$;

- COVID party / COVID-party, covid-party / covidparty, s.n. (do inglês COVID party), 1) 'reunião de pessoas com o intuito alegado de apanhar o coronavírus SARS-CoV-2', 2) 'qualquer reunião de muitas pessoas na época da pandemia da covid-19 em que se corre o risco de apanhar o coronavírus SARS-CoV-2” (ø); ex.: 1) “Jedni podważają istnienie COVID-19, inni wpadli już na pomysł urządzania covidparty, tak jak dawniej urządzano ospaparty." ${ }^{2}, 2$ ) "Każdy nauczyciel uczestniczący w tym covidparty powinien być pociągnięty do odpowiedzialności!" ${ }^{43}$;

- covidianin / kowidianin, s.m., covidianka / kowidianka, s.f. (derivado sufixal de covid / kowid, cf. inglês Covidian, francês covidien), 'pessoa que sobrevaloriza a gravidade da covid-19 e preocupa-se com a pandemia de forma exagerada, tomando medidas desnecessárias, como

38 "Antigo deputado negacionista em hospital com coronavírus", https://www.tvp.info/50888939/koronawirusjanusz-sanocki-zarazony.

39 "Encomende kits anticovid imprescindíveis em qualquer escritório!", https://inspirion.pl/news/pakietantycovidowy.

40 "Marcha dos negacionistas em Katowice", https://katowice24.info/antycovidowy-marsz-w-katowicach/.

41 "Vais ver um ano sem covid tão depressa como o Legia a ganhar o campeonato sem tramoias, ou seja, não neste século", http://www.90minut.pl/news/308/news3089670-Robert-Lewandowski-pilkarzem-roku-FIFA.html.

42 "Uns questionam a existência da COVID-19, outros já tiveram a ideia de organizar uma festa da covid-19, tal como antigamente se organizavam festas da varicela.", https://www.newsweek.pl/wiedza/zdrowie/sporo-juz-wiemy-okoronawirusie-mamy-spore-doswiadczenie-i-wlasnie-dlatego-nie/98jkfq4.

43 “Cada professor que participou nesta festa da covid-19 deveria ser responsabilizado por isso!”, https://sport. trojmiasto.pl/Wojewoda-nie-ma-postepowan-wobec-nauczycieli-po-protestach-n150347.html?strona=8\&vop=std. 
estocar papel higiénico' (NSP s.v. covidianin; WikiPL s.v. antymaseczkowiec, s.v. covidiota); ex.: "Zwykle tak odpowiadają covidianie, gdy ich spytasz o to, dlaczego noszą kaganiec, lub zatrzymujący cię ochroniarze z marketów, gdy zaczynasz recytować im konstytucję i swoje prawa." ${ }^{44}$

- covidianizm / kowidianizm, s.m. (derivado sufixal de covid / kowid, cf. inglês Covidianism, francês covidianisme, espanhol covidianismo), 'atitude de quem sobrevaloriza a gravidade da covid-19” (ø); ex.: “Covidianizm jako nowa religia”"45;

- covidiański / kowidiański, adj. (derivado sufixal de covid / kowid), 'relativo à atitude de quem sobrevaloriza a gravidade da covid-19 e preocupa-se com a pandemia de forma exagerada' (ø); ex.: "Z Waszych zapowiedzi wynika, że covidiański terror wam nie straszny i jako jedni z nielicznych nadal gracie koncerty." ${ }^{46}$;

- covidiota / kowidiota, s.m., covidiotka / kowidiotka, s.f. (hibridismo: covid / kowid + idiota, cf. inglês, francês covidiot, espanhol, italiano covidiota), 1) 'pessoa que nega a existência ou menospreza a gravidade da covid-19, desrespeita as recomendações do distanciamento social e outras medidas de segurança, aumentando o risco de contágio', 2) 'pessoa que sobrevaloriza a gravidade da covid-19 e preocupa-se com a pandemia de forma exagerada, tomando medidas desnecessárias, como estocar papel higiénico' (NSP s.v. covidiota (só na 1.a aceção); SJP c.v. covidiota (só na 1. a aceção); WikiPL s.v. covidiota (só na 1. a aceção)); ex.: 1) "Rośnie w siłę cały ruch negacjonistów pandemii, zwanych też antycovidowcami, foliarzami czy wręcz covidiotami." ${ }^{47}, 2$ ) "Opracowałem 20 najważniejszych słówek, terminów, fraz, którymi poczęstuje cię każdy covidiota." ${ }^{\text {; }}$;

- covidosceptycyzm / kowidosceptycyzm, s.m. (composto morfológico de covid / kowid + sceptycyzm, cf. inglês Covid scepticism, francês Covid-scepticisme, covidoscepticisme), 'atitude de quem nega a existência ou menospreza a gravidade da covid-19' (NSP s.v. covidowy); ex.: "O tym, jak covidosceptycyzm łączy się z innymi teoriami spiskowymi i jak je napędza." ${ }^{4}$;

- covidosceptyk / kowidosceptyk, s.m. (composto morfológico de covid / kowid + sceptyk, cf. francês covidosceptique), 'pessoa que nega a existência ou menospreza a gravidade da covid-19' (NSP s.v. covidowy; WikiPL s.v. denialista, s.v. koronasceptyk, s.v. sceptyk); ex.: "Całość uzupełnia antyszczepionkowiec i covidosceptyk, który w programie kontempluje obawy o rozprzestrzenianie się koronawirusa wśród uczestników Strajku Kobiet."50;

44 "Assim costumam responder os covidianos quando lhes perguntar porque vestem um açaime, ou os guardas nos supermercados quando começar a recitar-lhes a constituição e os seus direitos.", https://natemat.pl/321875, abecadlokoronasceptyka-czym-jest-kaganiec-a-kim-sa-covidianie-lista.

45 "O covidismo como nova religião" https://politywatory.com/2021/01/07/covidianizm-jako-nowa-religia/.

46 "Das vossas declarações depreende-se que vocês não temem o terror covidista e, como um dos poucos casos, continuam a dar concertos.", https://metalrevolt.net/wywiady/piec-pytan-do-andreasa-gerre-geremii-wokalisty-tankard/.

47 "O movimento inteiro dos negacionistas da pandemia, também chamados antycovidowcy, foliarze ou até covidiotas, torna-se cada vez mais forte., https://polskatimes.pl/antycovidowcy-foliarze-covidioci-negacjonisci-pandemii-mnozasie-niczym-wirus-prawie-co-piaty-polak-uwaza-ze-zadnej-pandemii/ar/c1-15237657.

48 "Elaborei 20 palavras, termos, frases mais importantes com as quais te vai servir qualquer covidiota.", https:// pieklomezczyzn.wordpress.com/2020/10/20/prosty-slownik-jezyka-covidianskiego/.

49 "Sobre como o coronacetisicmo está relacionado com outras teorias da conspiração e como as alimenta.", https:// www.facebook.com/MichalGiersz/posts/3633990169979762.

50 "A imagem é completada por um antivacina e coronacético que contempla no programa o receio de que o coronavírus se espalhe entre os participantes da Greve das Mulheres., https://www.geekweb.pl/rozrywka/item/1519motel-polska. 
- covidować / kowidować, v.intr./tr. (derivado sufixal de covid / kowid), 1) 'infetar ou contagiar com o coronavírus SARS-CoV-2, não respeitar as restrições impostas pela pandemia da covid-19', 2) 'estar doente de covid-19', 3) 'curar a covid-19, lutar contra a covid-19' (SJP s.v. covidować); ex.: 1) "A nie "covidować" się na siłowniach!”"51, 2) "Jej córkę (też kowidowała) niemal codziennie boli głowa." ${ }^{52}, 3$ ) "W te święta zamiast śpiewać kolędy będzie covidować w szpitalu, gdzie na co dzień jest pielęgniarką." ${ }^{53}$;

- covidowanie / kowidowanie, s.n. (derivado sufixal de covidować / kowidować), 1) 'ação de contagiar com o coronavírus SARS-CoV-2, não respeitar as restrições impostas pela pandemia da covid-19', 2) 'confinamento causado pela pandemia da covid-19' (ø); ex.: 1) “„Przepisy dotyczące dystansu społecznego i zakazu kowidowania będą oczywiście musiały być przestrzegane, ale sygnał jest naprawdę zachęcający” - dodał.” ${ }^{54}$; 2) „Po pół roku kowidowania domowego wróciłam do biura na 2 tygodnie." 55 ;

- covidowiec / kowidowiec, s.m. (derivado sufixal de covidowy / kowidowy), 1) 'pessoa doente de covid-19', 2) 'pessoa que sobrevaloriza a gravidade da covid-19 e preocupa-se com a pandemia de forma exagerada, tomando medidas desnecessárias, como estocar papel higiénico' (NSP s.v. covidowiec (só na 1. a aceção)); ex.: 1) "Wsparcie psychologiczne dla covidowców” ${ }^{\text {, }}$, 2) "Oprócz zniszczenia gospodarki, co za chwilę covidowcy odczujecie, nic kompletnie nie osiągnęliśmy." 57 ;

- COVID-owy, covidowy / kowidowy, adj. (derivado sufixal de covid / kowid), 'relativo à covid-19' (NSP s.v. covidowy; WikiPL s.v. covidowy); ex.: "Jak objawia się "covidowy język"?"58;

- covidyzm / kowidyzm, s.m. (derivado sufixal de covid / kowid, cf. inglês Covidism, francês covidisme), 'ideologia totalitária resultante da sobrevalorização da gravidade da covid-19, ameaçando a liberdade dos cidadãos' (ø); ex.: “Kowidyzm będzie trwał tak długo - aż nie zostanie obalony." 59 ;

- coviszkoła, s.f. (composto morfológico de covid + szkoła 'escola'), 'educação à distância causada pela pandemia da covid-19' (SJP s.v.); ex.: “Jednak po miesiącach koronatime, coviszkoły,

51 “E não contagiarem com o coronavírus uns aos outros nos ginásios!” https://poznan.wyborcza.pl/ poznan/7,36001,26764567,granice-cierpliwosci-zostaly-przekroczone-silownie-w-calej.html.

52 "À filha dela (que também esteve doente de covid-19) dói-lhe a cabeça quase todos os dias.", https://twitter.com/ Firarafaa/status/1309210686250192899/photo/1.

53 "Neste Natal, em vez de cantar canções natalinas, vai lutar contra a covid-19 no hospital onde trabalha diariamente como enfermeira." http://bibsy.pl/D2xKDZS2/w-te-swieta-zamiast-spiewac-koledy-bedzie-covidowac-w-szpitalu-gdziena-co-dzien-jest-pielegniarka-taka-decyzje-szanuje.

54 “' “Obviamente, as leis referentes ao distanciamento social e à proibição de contagiar com o coronavírus vão ter que ser respeitadas, mas o sinal é deveras convidativo" - acrescentou., https://www.f1-fansite.com/pl/f1-news/speed-of-imolaticket-sales-exciting/.

55 “Após seis meses de confinamento em casa causado pela covid-19 voltei ao escritório por 2 semanas." http:// klarkamrozek.blogspot.com/2020/11/co-nam-jeszcze-wolno.html.

56 "Apoio psicológico para doentes de covid-19", https://radioszczecin.pl/1,415036,wsparcie-psychologiczne-dlacovidowcow.

57 "Para além da destruição da economia, o que daqui a pouco vão sentir, covidistas, não conseguimos absolutamente nada., https://plonskwsieci.pl/pl/697_koronawirus/6678_prof-gut-to-nie-wirus-sie-roznosi-tylko-my-go-roznosimy.html.

58 “Como se manifesta a "língua covid"?", https://www.medonet.pl/koronawirus/to-musisz-wiedziec,koronawirus--objawy--lekarz-wskazuje-nowy-symptom--covidowy-jezyk,artykul,13566356.html.

59 “A ideologia covid existirá até ser derrubada., http://zaprasza.net/a.php?article_id=36402. 
pracy zdalnej i kilku lockdownach spektakl przestał być ściągawką dla rodziców z tego, co robią ich dzieci w sieci i stał się opowieścią o każdym z nas, bez względu na wiek - o ludziach wyrzuconych z realnego codziennego życia i w zamian zanurzonych w internecie." ${ }^{\circ}$;

- niecovidowy / niekowidowy, adj. (derivado prefixal de covidowy / kowidowy, cf. inglês nonCOVID), 1) 'não relacionado com a covid-19', 2) 'que não tem covid-19' (ø); ex.: 1) 'Pielęgniarka oddziału niecovidowego" ${ }^{1}, 2$ ) "Narodowa Hekatomba niekowidowych Polaków trwa"62;

- odcovidować / odkowidować, v.tr. (derivado prefixal de covidować / kowidować), 'voltar a transformar um estabelecimento dedicado ao tratamento de doentes de covid-19 num estabelecimento geral' (ø); ex.: "I oto decyzja z ostatnich dni o tym, żeby, kolokwialnie mówiąc, odcovidować część łóżek szpitalnych, czyli zrezygnować z niektórych punktów, które miały specjalistycznie być tylko dla tego poświęcone, no bo trzeba też leczyć Polaków na rozmaite inne choroby." ${ }^{63}$;

- odcovidowanie / odkowidowanie, s.n. (derivado sufixal de odcovidować / odkowidować), 'ação ou resultado de voltar a transformar um estabelecimento dedicado ao tratamento de doentes de covid-19 num estabelecimento geral' (ø); ex.: "Zarząd powiatu podjął w lipcu uchwałę o wezwaniu wojewody śląskiego do „odcovidowania” szpitala, czyli przekształcenia go z powrotem w lecznicę dla wszystkich pacjentów, a nie tylko tych chorujących na koronawirusa." ${ }^{64}$;

- pocovidowiec / pokowidowiec, s.m. (derivado sufixal de pocovidowy / pokowidowy), 'pessoa que já teve covid-19’ (ø); ex.: ““"Pocovidowcy” uskarżają się zwłaszcza na bóle głowy”65;

- pocovidowy / pokowidowy, adj. (derivado prefixal de covidowy / kowidowy, cf. inglês postCovid), 'relativo à realidade posterior à pandemia da covid-19' (ø); ex.: “Pocovidowa choroba niezwykle groźna dla dzieci"66;

- postcovidowy / postkowidowy, adj. (do inglês post-Covid), 'relativo à realidade posterior à pandemia da covid-19' (WikiPL s.v. postcovidowy); ex.: "Rehabilitacja postcovidowa to połączenie fizjoterapii oddechowej oraz ogólnousprawniającej." ${ }^{3}$;

60 "Contudo, após meses de koronatime, educação à distância, teletrabalho e alguns confinamentos, o espetáculo deixou de ser cábula para os pais daquilo que os filhos deles fazem na rede e tornou-se uma narrativa sobre cada um de nós, independentemente da idade - sobre pessoas expulsas da vida real quotidiana e, em vez disso, imergidas na internet.", https://www.terazteatr.pl/aktualnosci/ferie-z-olsztynskim-teatrem-jaracza,5724,3.

61 "Enfermeira de um departamento não-covid", https://www.medexpress.pl/niecovidowy-oddzial/79908.

62 "A Hecatombe Nacional dos polacos sem covid continua", http://ewaryst-fedorowicz.szkolanawigatorow.pl/ narodowa-hekatomba-niekowidowych-polakow-trwa.

63 "E eis a decisão dos últimos dias de, falando coloquialmente, voltar a transformar uma parte dos lugares em hospitais em lugares gerais, quer dizer, desistir de alguns sítios que haviam de ser dedicados só e especificamente a isso, pois é preciso também curar os polacos de várias outras doenças.", https://www.polskieradio.pl/7/129/Artykul/2652375.

64 "Em julho, a direção do concelho adotou a resolução de apelar ao voivoda da Silésia para voltar a transformar o hospital num hospital geral, ou seja, voltar a transformá-lo num hospital para todos os pacientes, não só aqueles que estão doentes com coronavírus.", http://www.nowinyraciborskie.pl/e/2020-08-25/164095-odcovidowanie-szpitala-wraciborzu-wrzesien-to-realny-termin.html.

65 "As pessoas que já tiveram covid-19 queixam-se sobretudo de dores de cabeça", https://bydgoszcz.tvp.pl/52007148/ ozdrowiency-skarza-sie-na-bole.

66 "A doença pós-covid é particularmente perigosa para crianças", https://www.tvp.info/52172434/mis-cwieloukladowy-zespol-zapalny-pocovidowa-choroba-niezwykle-grozna-dla-dzieci.

67 “Reabilitação pós-covid é uma junção de fisioterapia respiratória e geral." https://carolina.pl/rehabilitacjapostcovidowa/. 
- przedcovidowy / przedkowidowy, adj. (derivado prefixal de covidowy / kowidowy, cf. inglês pre-Covid), 'relativo à realidade anterior à pandemia da covid-19' (ø); ex.: “Ponieważ wiele Organizacji obawia się otwierania tak potencjalnie trudnych i szerokich pól negocjacji z pracownikami to bez wątpienia powstanie pokusa, aby przywrócić "przedkowidowy” sposób działania zaraz po wygaśnięciu epidemicznych specustaw." ${ }^{68}$;

- zacovidować / zakowidować, v.tr. (derivado prefixal de covidować / kowidować), 'dedicar um estabelecimento só ao tratamento de doentes de covid-19' (ø); ex.: "Nie wolno zakowidować całego szpitala!!!"69;

- zacovidowanie / zakowidowanie, s.n. (derivado sufixal de zacovidować / zakowidować), 'ação ou resultado de infetar ou contagiar com o coronavírus SARS-CoV-2' (ø); ex.: "Winda w szpitalu jest sprawna i celowo wyłączona na wypadek jej zakowidowania przez przygodnego pasażera, co pociągnęłoby duży koszt jej odkażania (wielokrotnego - za każdym zakowidowaniem)." ${ }^{\prime 70}$.

\subsection{Observações}

Dentro do corpus foram encontrados 22 itens em português e 25 em polaco. São maioritariamente substantivos e adjetivos, registando-se também alguns verbos. Alguns deles, supostamente os mais frequentes, já se encontram inclusive dicionarizados (pt. anticovid, covid-drive, covidário, covidiano, covídico; pol. covidianin, covidiota, covidosceptyk, covidowy, postcovidowy).

Quanto à etimologia, os neologismos recolhidos podem ser classificados da seguinte maneira:

- empréstimos do inglês: pt. covid-drive, Covidexit, pol. COVID party / COVID-party, covid-party / covidparty, postcovidowy / postkowidowy;

- internacionalismos por empréstimo ou decalque:

- derivados prefixais: pt. anticovid(-19), não-covid(-19), pós-covid(-19), pré-covid(-19), pol. antycovidowy / antykowidowy, bezcovidowy / bezkowidowy, niecovidowy / niekowidowy, pocovidowy / pokowidowy, przedcovidowy / przedkowidowy;

- derivados sufixais: pt. covidiano, covidismo, covidista, pol. antycovidowiec / antykowidowiec, covidianin / kowidianin, covidianizm / kowidianizm, covidyzm / kowidyzm;

- compostos morfológicos: pt. covidmaníaco, Covidolândia, pol. covidosceptycyzm / kowidosceptycyzm, covidosceptyk / kowidosceptyk;

- hibridismos: pt. covidioma, covidiota, covidivórcio, pol. covidiota / kowidiota;

68 "Como muitas Organizações têm receio de abrir campos de negociação com trabalhadores, potencialmente tão difíceis e vastos, nascerá indubitavelmente a tentação de voltar ao modo de atuação "pré-covid" logo depois de as leis especiais da epidemia caducarem.", http://www.outsourcingportal.eu/pl/blog/karina-kreja/biuro-2021-utrwalenie-pracyzdalnej.

69 "Não se deve transformar num covidário o hospital inteiro!!!", https://tomaszow.lub.pl/forum/viewtopic. php?t=135840\&start $=450$.

70 "O elevador no hospital está operacional e está propositadamente desativado no caso de algum passageiro casual o infetar com o coronavírus, o que implicaria grandes custos de desinfeção (múltipla - uma por cada infeção)." https:// zyciesokolowa.pl/pl/19_wiadomosci_z_regionu/6608_powiat-sokolowski-dofinansuje-opracowanie-projektu-mostu-nabugu.html. 
- criações internas por:

- derivação sufixal: pt. covidade, covidário, covidês, covídico, pol. covidiański / kowidiański, covidować / kowidować, covidowanie / kowidowanie, covidowiec / kowidowiec, covidowy / kowidowy, pocovidowiec / pokowidowiec;

- derivação prefixal: odcovidować / odkowidować, odcovidowanie / odkowidowanie, zacovidować / zakowidować, zacovidowanie / zakowidowanie;

- derivação imprópria: pt. covidar;

- composição morfológica: pol. coviszkoła.

Como se pode observar, predominam quantitativamente os internacionalismos que, muitas vezes, têm a sua origem em inglês (cf. Roig-Marín 2020: 2) e também já se registam em várias outras línguas. Para além deles e de poucos anglicismos, observam-se vários vocábulos formados com a ajuda de recursos morfológicos disponíveis e produtivos em cada uma das línguas.

Os termos analisados apresentam diferentes graus de assimilação gráfica, fenómeno que está relacionado com a sua frequência. Os mais usados (como pt. covid, covídico, covidiano, covidiota, pol. covid / kowid, covidowy / kowidowy, covidiota / kowidiota, covidianin / kowidianin) escrevemse como as palavras vernáculas. As eventuais hesitações dos falantes acerca da aceitabilidade dos termos mais recentes ou raros, logo, sentidos por alguns como estranhos ao léxico, costumam exprimir-se na escrita através de aspas ou itálicos. Acrescente-se que em polaco, quase todos os itens analisados (salvo COVID party / COVID-party, covid-party / covidparty e coviszkoła) têm variantes alográficas: uma com base na forma original inglesa (covid) e outra polonizada (kowid), embora a frequência das primeiras pareça, por enquanto, prevalecer.

No que tange à semântica dos vocábulos recolhidos, eles referem-se geralmente ou à própria covid-19 (termos neutrais), ou a atitudes humanas perante a pandemia consideradas como extremas (termos avaliativos). Este grupo de significados exprime-se em ambas as línguas, como se pode ver na tabela 1 .

\begin{tabular}{|c|c|c|}
\hline significado & português & polaco \\
\hline \multirow{3}{*}{ 'relativo à covid-19' } & covidiano & \multirow{3}{*}{$\begin{array}{l}\text { COVID-owy, covidowy / kowi- } \\
\text { dowy }\end{array}$} \\
\hline & covídico & \\
\hline & covid(-19) & \\
\hline $\begin{array}{l}\text { 'que não é relativo à covid-19; não causado } \\
\text { pela covid-19' }\end{array}$ & $\begin{array}{l}\text { não-covid(-19)/ } \\
\text { não covid(-19) }\end{array}$ & niecovidowy / niekowidowy \\
\hline $\begin{array}{l}\text { 'relativo à realidade anterior à pandemia } \\
\text { da covid-19' }\end{array}$ & pré-covid(-19) & przedcovidowy / przedkowidowy \\
\hline \multirow{2}{*}{$\begin{array}{l}\text { 'relativo à realidade posterior à pandemia } \\
\text { da covid-19' }\end{array}$} & \multirow{2}{*}{ pós-covid(-19) } & pocovidowy / pokowidowy \\
\hline & & postcovidowy / postkowidowy \\
\hline $\begin{array}{l}\text { 'destinado a combater ou proteger contra } \\
\text { a covid-19' }\end{array}$ & anticovid(-19) & antycovidowy / antykowidowy \\
\hline \multirow{3}{*}{$\begin{array}{l}\text { 'pessoa que nega a existência ou menospreza } \\
\text { a gravidade da covid-19' }\end{array}$} & \multirow{3}{*}{ covidiota } & antycovidowiec / antykowidowiec \\
\hline & & $\begin{array}{l}\text { covidiota / kowidiota, } \\
\text { covidiotka / kowidiotka }\end{array}$ \\
\hline & & covidosceptyk / kowidosceptyk \\
\hline
\end{tabular}




\begin{tabular}{|c|c|c|}
\hline significado & português & polaco \\
\hline $\begin{array}{l}\text { 'que nega a existência ou menospreza a gravidade } \\
\text { da covid-19' }\end{array}$ & covidiota & antycovidowy / antykowidowy \\
\hline \multirow{3}{*}{$\begin{array}{l}\text { 'pessoa que sobrevaloriza a gravidade } \\
\text { da covid-19' }\end{array}$} & covidiota & $\begin{array}{l}\text { covidiota / kowidiota, } \\
\text { covidiotka / kowidiotka }\end{array}$ \\
\hline & covidista & $\begin{array}{l}\text { covidianin / kowidianin, } \\
\text { covidianka / kowidianka }\end{array}$ \\
\hline & covidmaníaco & covidowiec / kowidowiec \\
\hline \multirow{3}{*}{$\begin{array}{l}\text { 'que sobrevaloriza a gravidade } \\
\text { da covid-19' }\end{array}$} & covidiota & \multirow{3}{*}{ covidiański / kowidiański } \\
\hline & covidista & \\
\hline & covidmaníaco & \\
\hline $\begin{array}{l}\text { 'atitude de quem sobrevaloriza a gravidade da } \\
\text { covid-19' }\end{array}$ & covidismo & covidianizm / kowidianizm \\
\hline
\end{tabular}

Tabela 1. Conceitos que têm nomes em ambas as línguas.

No entanto, também não faltam significados que só têm nomes numa das línguas analisadas. Neste caso, não se trata apenas de vários conceitos específicos relacionados tecnicamente com a doença em si, mas também daqueles que referem elementos particulares da realidade da pandemia da covid-19. Parece que o surgimento dos neologismos agrupados aqui se deve quer à importação de termos estrangeiros (p.ex. pt. covidivórcio, covid-drive, pol. covidosceptycyzm / kowidosceptycyzm, covidyzm / kowidyzm), quer à criatividade dos falantes auxiliada pelo conjunto de recursos morfológicos e lexicais disponíveis em português e em polaco (p.ex. pt. covidar, covidês, covidice, pol. covidować / kowidować, zacovidować / zakowidować, odcovidować / odkowidować). Confiram-se as tabelas 2 e 3.

\begin{tabular}{|c|c|}
\hline significado & vocábulo português \\
\hline 'realidade anterior à pandemia da covid-19' & pré-covid(-19) \\
\hline 'realidade posterior à pandemia da covid-19' & pós-covid(-19) \\
\hline $\begin{array}{l}\text { 'centro de testes à covid-19 em que o utente é testado sem ter de sair do seu } \\
\text { automóvel' }\end{array}$ & covid-drive \\
\hline $\begin{array}{l}\text { 'espaço hospitalar onde se recebem e tratam doentes suspeitos ou portadores do } \\
\text { coronavírus' }\end{array}$ & covidário \\
\hline 'terra em que se registam muitos casos de covid-19' & Covidolândia \\
\hline \multirow{2}{*}{$\begin{array}{l}\text { 'linguagem particular, especificamente em termos de vocabulário, usada para } \\
\text { descrever a realidade da pandemia da covid-19' }\end{array}$} & covidês \\
\hline & covidioma \\
\hline $\begin{array}{l}\text { 'palavra ou expressão típica da linguagem usada para descrever a realidade da } \\
\text { pandemia da covid-19' }\end{array}$ & covidismo \\
\hline $\begin{array}{l}\text { 'aquilo que se faz na época pandemia da covid-19 e que nunca se tinha feito } \\
\text { antes' }\end{array}$ & covidice \\
\hline
\end{tabular}




\section{significado}

'ter momentos de convívio com outras pessoas, à distância ou não, na época da pandemia da covid-19’

'separação conjugal resultante do confinamento em casa imposto por causa da pandemia da covid-19'

'delírio causado pela pandemia da covid-19'

'disseminação da covid-19 no meio dos desportistas que afeta o rendimento das equipas'

'saída das restrições do período da pandemia da covid-19' vocábulo português

covidar

covidivórcio

covidelírio

covidade desportiva

Tabela 2. Conceitos que têm nomes em português.

\begin{tabular}{|c|c|}
\hline significado & vocábulo polaco \\
\hline $\begin{array}{l}\text { 'infetar ou contagiar com o coronavírus SARS-CoV-2, não respeitar as } \\
\text { restrições impostas pela pandemia da covid-19' }\end{array}$ & covidować / kowidować \\
\hline $\begin{array}{l}\text { 'ação de contagiar com o coronavírus SARS-CoV-2, não respeitar as } \\
\text { restrições impostas pela pandemia da covid-19' }\end{array}$ & covidowanie / kowidowanie \\
\hline 'ação ou resultado de infetar ou contagiar com o coronavírus SARS-CoV-2' & zacovidowanie / zakowidowanie \\
\hline 'curar a covid-19, lutar contra a covid-19' & covidować / kowidować \\
\hline 'estar doente de covid-19' & covidować / kowidować \\
\hline 'pessoa doente de covid-19' & covidowiec / kowidowiec \\
\hline 'pessoa que já teve covid-19' & pocovidowiec / pokowidowiec \\
\hline 'dedicar um estabelecimento só ao tratamento de doentes de covid-19' & zacovidować/zakowidować \\
\hline $\begin{array}{l}\text { 'voltar a transformar um estabelecimento dedicado ao tratamento de } \\
\text { doentes de covid-19 num estabelecimento geral' }\end{array}$ & odcovidować / odkowidować \\
\hline $\begin{array}{l}\text { 'ação ou resultado de voltar a transformar um estabelecimento dedicado } \\
\text { ao tratamento de doentes de covid-19 num estabelecimento geral' }\end{array}$ & $\begin{array}{l}\text { odcovidowanie / } \\
\text { odkowidowanie }\end{array}$ \\
\hline \multirow{2}{*}{ 'que não tem covid-19, em que não há covid-19' } & bezcovidowy / bezkowidowy \\
\hline & niecovidowy / niekowidowy \\
\hline $\begin{array}{l}\text { 'atitude de quem nega a existência ou menospreza a gravidade } \\
\text { da covid-19' }\end{array}$ & $\begin{array}{l}\text { covidosceptycyzm / } \\
\text { kowidosceptycyzm }\end{array}$ \\
\hline $\begin{array}{l}\text { 'ideologia totalitária resultante da sobrevalorização da gravidade da } \\
\text { covid-19, ameaçando a liberdade dos cidadãos' }\end{array}$ & covidyzm / kowidyzm \\
\hline 'confinamento causado pela pandemia da covid-19' & covidowanie / kowidowanie \\
\hline $\begin{array}{l}\text { 'reunião de pessoas com o intuito alegado de apanhar o coronavírus } \\
\text { SARS-CoV-2' }\end{array}$ & $\begin{array}{l}\text { COVID party / COVID-party, } \\
\text { covid-party / covidparty }\end{array}$ \\
\hline $\begin{array}{l}\text { 'qualquer reunião de muitas pessoas na época da pandemia da covid-19 } \\
\text { em que se corre o risco de apanhar o coronavírus SARS-CoV-2' }\end{array}$ & $\begin{array}{l}\text { COVID party / COVID-party, } \\
\text { covid-party / covidparty }\end{array}$ \\
\hline 'educação à distância causada pela pandemia da covid-19' & coviszkoła \\
\hline
\end{tabular}

Tabela 3. Conceitos que têm nomes em polaco. 
Existem várias relações semânticas entre os termos analisados. Por um lado, observam-se casos de sinonímia absoluta, nomeadamente, usam-se vários termos para designar exatamente o mesmo conceito, o que, do ponto de vista do sistema lexical, pode ser considerado redundante, p.ex.:

- 'relativo à covid-19': pt. covidiano, covídico e covid(-19);

- 'linguagem da pandemia da covid-19': pt. covidês e covidioma;

- 'relativo à realidade posterior à pandemia da covid-19': pol. pocovidowy / pokowidowy e postcovidowy / postkowidowy);

- 'que não tem covid-19, em que não há covid-19': pol. bezcovidowy / bezkowidowy e niecovidowy / niekowidowy.

Noutros casos, surgem nuances entre os sinónimos; isso diz respeito aos termos avaliativos que referem as atitudes radicais das pessoas perante a pandemia, p.ex. 'pessoa que sobrevaloriza a gravidade da covid-19' é covidiota, covidista ou covidmaníaco em português e covidiota / kowidiota, covidianin / kowidianin ou covidowiec / kowidowiec em polaco.

Por outro lado, encontram-se exemplos de polissemia e o significado do vocábulo só pode ser precisado pelo contexto. Tal é, entre outros, o caso do substantivo português covidismo (1) 'palavra, expressão', 2) 'atitude') e do verbo polaco covidować / kowidować (1) 'infetar, contagiar', 2) 'estar doente', 3) 'curar'). Além disso, é curioso constatar que o significado do neologismo avaliativo covidiota, tanto em português como em polaco, depende de quem o usa, podendo referir conceitos precisamente opostos: 1) para os que levam a pandemia a sério e seguem as recomendações dos médicos, cientistas e governos, é alguém irresponsável que nega ou menospreza a gravidade da covid-19, colocando os outros e a si mesmo em risco de contágio; 2) para os partidários das teorias da conspiração segundo as quais a pandemia foi planeada e a covid-19 não é mais do que uma gripe ou constipação, é uma pessoa crédula e fácil de manipular, que exagera nas precauções de segurança que toma para se proteger do coronavírus. Em ambos os casos, o termo é bastante depreciativo e até desdenhoso, mostrando a polarização da sociedade quanto às atitudes perante a pandemia.

Finalmente, embora os neologismos aqui analisados não divirjam muito em português e em polaco, sendo até intuitivamente compreensíveis para quem não sabe falar a outra língua, apontemos para os falsos amigos que se podem detetar no corpus. Veja-se a tabela 4.

\begin{tabular}{|c|c|}
\hline português & polaco \\
\hline $\begin{array}{l}\text { covidismo 'palavra ou expressão típica da } \\
\text { linguagem usada para descrever a realidade da } \\
\text { pandemia da covid-19' }\end{array}$ & \multirow{2}{*}{$\begin{array}{l}\text { covidyzm / kowidyzm 'ideologia totalitária } \\
\text { resultante da sobrevalorização da gravidade da } \\
\text { covid-19, ameaçando a liberdade dos cidadãos' }\end{array}$} \\
\hline $\begin{array}{l}\text { covidismo 'atitude de quem sobrevaloriza } \\
\text { a gravidade da covid-19' }\end{array}$ & \\
\hline \multirow{2}{*}{ covidiano 'relativo à covid-19' } & $\begin{array}{l}\text { covidianin / kowidianin 'pessoa que sobrevaloriza } \\
\text { a gravidade da covid-19' }\end{array}$ \\
\hline & $\begin{array}{l}\text { covidiański / kowidiański 'que sobrevaloriza } \\
\text { a gravidade da covid-19’ }\end{array}$ \\
\hline
\end{tabular}




\begin{tabular}{|c|c|}
\hline português & polaco \\
\hline \multirow{3}{*}{$\begin{array}{l}\text { covidar 'ter momentos de convívio com outras } \\
\text { pessoas, à distância ou não, na época da pandemia } \\
\text { da covid-19' }\end{array}$} & $\begin{array}{l}\text { covidować / kowidować 'infetar ou contagiar } \\
\text { com o coronavírus SARS-CoV-2, não respeitar as } \\
\text { restrições impostas pela pandemia da covid-19' }\end{array}$ \\
\hline & covidować / kowidować 'estar doente de covid-19' \\
\hline & $\begin{array}{l}\text { covidować / kowidować 'curar a covid-19, lutar } \\
\text { contra a covid-19' }\end{array}$ \\
\hline
\end{tabular}

Tabela 4. Falsos amigos identificados no corpus.

Para além disso, há também falsos amigos parciais, nomeadamente, termos que têm um significado em comum e outro não. Assim, ao adjetivo polaco antycovidowy / antykowidowy na aceção 'destinado a combater ou proteger contra a covid-19' corresponde o adjetivo português anticovid(-19) 'id.', mas se se quiser traduzir a aceção 'que nega a existência ou menospreza a gravidade da covid-19', é preciso usar o adjetivo português covidiota. Do mesmo modo, o adjetivo polaco niecovidowy / niekowidowy na aceção 'que não é relativo à covid-19; não causado pela covid-19' tem o seu homólogo português não-covid(-19) / não covid(-19) 'id.', mas à sua segunda aceção 'que não tem covid-19, em que não há covid-19' não corresponde em português nenhum termo do corpus.

\section{Conclusão}

A pandemia da covid-19 fez com que se divulgassem e internacionalizassem certos usos linguísticos específicos e repetitivos, sobretudo no que toca ao vocabulário. Essa nova linguagem, o "covidioma" ou "covidês", continua a formar-se a olhos vistos, a uma velocidade vertiginosa; retomando as palavras de Leal de Barros (2020), pode-se dizer que é uma língua-relâmpago com um grande potencial contagioso. Independentemente da atitude que se tenha para com os neologismos, admita-se que é um processo fascinante de testemunhar e explorar.

Os "covidismos" analisados constituem apenas um pequeno fragmento da riqueza dos termos que foram forjados em português e em polaco para referir vários elementos da realidade da pandemia da covid-19. Nas duas línguas tidas em conta abundam novos empréstimos, internacionalismos e criações internas que nasceram ou têm vindo a ganhar relevo nos últimos doze meses, p.ex. pt. coronacético '(pessoa) que nega a existência ou menospreza a gravidade da covid-19', infodemia 'fluxo intenso e rápido de muitas informações, fidedignas ou não, sobre determinado assunto', telescola 'educação à distância'; pol. bezmaseczkowiec 'pessoa que se recusa a usar a máscara, embora tal seja obrigatório', plandemia 'pandemia falsa, planeada por elites', teleporada 'consulta médica à distância'. Obviamente, outras línguas também estão a alargar o seu léxico; citem-se só mais dois exemplos interessantes de "coroneologismos" (Roig-Marín 2020: 2): inglês quarantini 'coquetel bebido durante o confinamento' (quarantine + martini) e espanhol Zoompleaños 'aniversário festejado em linha' (Zoom + cumpleaños). 
É preciso ter em conta que os vocábulos reunidos por nós, tal como todos os outros neologismos relativos à covid-19, estão a gozar de grande vitalidade num momento em que a pandemia ainda está longe de ser combatida. No entanto, a situação continua dinâmica e pode mudar rapidamente, implicando, como é de esperar, mudanças na língua. Por um lado, talvez a palavra covid, entre outras, venha a originar mais termos referentes à realidade pandémica; por outro lado, esses neologismos, tanto os já existentes como os futuros, poderão ser efémeros e acabar por cair em desuso quando a pandemia terminar (cf. p.ex. Gawina 2020). Seja como for, um ano depois de o coronavírus SARS-CoV-2 se ter alastrado pelo mundo fora, o "covidioma" ou "covidês" continua a forjar-se, com o seu caráter global e toques locais particulares, hesitações e imprecisões na forma e no significado dos seus termos, satisfazendo as necessidades e refletindo a criatividade linguística das pessoas.

Como diz Jabłonka (2016: 33), “O léxico de uma língua constitui um conjunto de experiências multisseculares vividas pelas comunidades falantes desta.” É bem provável que pelo menos alguns dos "covidismos" analisados no presente estudo se fixem em português e em polaco e venham a contribuir, deste modo, para a gravação dos acontecimentos da história universal do ano 2020 e posteriores na memória coletiva dos luso- e polonófonos.

\section{Referências bibliográficas}

Alvarez, L. (2020). Dicionário da covid-19, as palavras que queremos deixar de dizer. Público, 03/05/2020, $<$ https://www.publico.pt/2020/05/03/politica/noticia/dicionario-covid19-palavras-queremos-deixar-dizer-1914840>

Araújo Pereira, R. (2020). O covidioma. Visão, 1436. <https://visao.sapo.pt/opiniao/cronicas/boca-do-inferno/2020-09-15-o-covidioma/>

[Aulete]: Dicionário Aulete. <http://www.aulete.com.br/>

Belhaj, S. (2020). La pandémie Covid-19 et lémergence d'un nouveau technolecte. Langues, cultures et sociétés, 6, 1, 28-38.

Bloch, N. (2020). Korona-słownik, czyli zabawa słowem. Czym jest "kawantanna"? Dzień Dobry TVN, 07/04/2020 <https://dziendobry.tvn.pl/a/korona-slownik-czyli-zabawa-slowem-podczas-domowej-kwarantanny $>$

Caminha, L. (2020). Quadra 76. ocasos - luis caminha-antóneo. <http://ocasosluiscaminha.blogspot. com/2020/11/quadra-76.html>

[CDLP]: O léxico da covid-19 (texto anónimo). Ciberdúvidas da Língua Portuguesa. <https://ciberduvidas. iscte-iul.pt/artigos/rubricas/idioma/o-lexico-da-covid-19/4059>

Cierpich-Kozieł, A. (2020). Koronarzeczywistość - o nowych złożeniach z członem korona- w dobie pandemii. Język Polski, C/4, 102-117. DOI: 10.31286/JP.100.4.7.

[Dicio]: Dicionário Online de Português. <https://www.dicio.com.br/>

[DPLP]: Dicionário Priberam da Língua Portuguesa. <https://dicionario.priberam.org/>

Einstein-Schweriner, M. R. (2021). Esquizocovidfrenia. Estadão, 06/02/2021 <https://politica.estadao.com. br/blogs/fausto-macedo/esquizocovidfrenia/> 
Gaglioni, C. (2020). Como a pandemia expandiu o nosso vocabulário. Nexo, 13/05/2020. <https://www.nexojornal.com.br/expresso/2020/05/12/Como-a-pandemia-expandiu-nosso-vocabul\%C3\%A1rio>

Gawina, M. (2020). Koronawirus ubrany w słowa, czyli wpływ pandemii na nasz język - okiem eksperta z UwB. Uniwersytet w Białymstoku, 24/09/2020. <https://uwb.edu.pl/nowosci/okiem-eksperta/koronawirus-ubrany-w-slowa-czyli-wplyw-pandemii-na-nasz-jezyk-okiem-eksperta-z-uwb/3fa90445>

Gębka-Wolak, M. (2020). Jak polszczyzna radzi sobie z koronawirusem? O środkach językowych wykorzystywanych do opisu rzeczywistości w czasie pandemii. Dyskurs \& Dialog, 4, 159-173. DOI: 10.5281/ zenodo.4337408.

[Infopédia]: Infopédia. Dicionários Porto Editora. <https://www.infopedia.pt/>

Jabłonka, E. (2016). Introdução das unidades lexicais estrangeiras no português atual. Estudo baseado em blogues femininos portugueses e brasileiros. Lublin: Wydawnictwo Uniwersytetu Marii Curie-Skłodowskiej.

Kuligowska, K. (2020). Język w czasach zarazy. O wpływie pandemii na system leksykalny języka polskiego i rosyjskiego. Acta Polono-Ruthenica, XXV, 3, 109-126. DOI: 10.31648/apr.5893.

Lasalle, G. (2020). La pandémie a-t-elle enrichi votre vocabulaire? Radio-Canada, 19/09/2020. <https://ici. radio-canada.ca/nouvelle/1734470/langue-francaise-covidiot-mots-langage-pandemie-coronavirus-covid-expressions>

Leal de Barros, A. (2020). Testar ou não testar, eis a questão. In A. Martingo (coord.), ILCH em Notícia. Boletim Informativo, 7, Edição Especial. <https://www.ilch.uminho.pt/pt/Instituto/Documents/ILCH_noticia_7.pdf>

Leiser Baronas, R.; Oliveira Carreon, R. de; \& Fernandes dos Santos Silva, S. (Orgs.) (2020). Linguasagem, 35, 1, número temático: COVID-19: uma pandemia sob o olhar das ciências da linguagem.

Lexicovid-19. Dicionário Enciclopédico do Novo Coronavírus. <https://www.lexicovid19.com.br/>

[LOD]: Covid-19-Glossaire. Lëtzebuerger Online Dictionnaire, Erausgi vum Zenter fir d'Lëtzebuerger Sprooch (Educatiounsministère). <https://www.lod.lu/covid-19/>

Marin La Meslée, V. (2020). Petit abécédaire des mots qui nous assaillent en temps de pandémie. Le Point, 18/04/2020. <https://www.lepoint.fr/societe/petit-abecedaire-des-mots-qui-nous-assaillent-en-tempsde-pandemie-18-04-2020-2371947_23.php>

Marques, V. D. M. V. (2020). Em meio ao medo brota-se a linguagem. UNEMAT. Universidade do Estado de Mato Grosso, 20/11/2020. <http://sinop.unemat.br/site/2020/11/em-meio-ao-medo-brota-se-a-linguagem/>

Martingo, A. (Coord.) (2020). ILCH em Notícia. Boletim Informativo, 7, maio 2020, Edição Especial. <https:// www.ilch.uminho.pt/pt/Instituto/Documents/ILCH_noticia_7.pdf >

Melo de Sousa, A.; Santos Junior, J. R. dos; \& Queiroz de Lima, I. (2020). Expansão lexical em Libras no contexto do coronavírus. Papéis: Revista do Programa de Pós-Graduação em Estudos de Linguagens - UFMS, 24, Número Especial, 72-96.

Moran, P. (2020). Covidiots? Quarantinis? Linguist explains how COVID-19 has infected our language. CBC/ Radio-Canada, 22/04/2020. <https:/www.cbc.ca/radio/thecurrent/the-current-for-april-22-2020-1.5540906/ covidiots-quarantinis-linguist-explains-how-covid-19-has-infected-our-language-1.5540914>

[NSP]: Czeszewski, M. (Ed.). Obserwatorium Językowe Uniwersytetu Warszawskiego. Najnowsze Stownictwo Polskie. <https://nowewyrazy.pl/>

[OED1]: OED Editorial. Corpus analysis of the language of Covid-19. Oxford English Dictionary, 15/04/2020, $<$ https://public.oed.com/blog/corpus-analysis-of-the-language-of-covid-19/>

[OED2]: OED Editorial. Using corpora to track the language of Covid-19: update 2. Oxford English Dictionary, 15/07/2020 <https://public.oed.com/blog/using-corpora-to-track-the-language-of-covid-19-update-2/> 
Ribeiro Ferreira, L. (2020). A criatividade lexical de uma pandemia. 7 Margens, 26/05/2020. <https://setemargens.com/a-criatividade-lexical-de-uma-pandemia/>

Ro, Ch. (2020). Why we've created new language for coronavirus. BBC, 25/05/2020. <https://www.bbc.com/ worklife/article/20200522-why-weve-created-new-language-for-coronavirus>

Roig-Marín, A. (2020). English-based coroneologisms: A short survey of our Covid-19-related vocabulary. English Today, 1-3. DOI: 10.1017/S0266078420000255.

Salazar, D. (2020). Circuit breakers, PPEs, and Veronica buckets: World Englishes and Covid-19. Oxford English Dictionary, 07/05/2020. <https://public.oed.com/blog/circuit-breakers-ppes-veronica-buckets-world-englishes-covid-19/>

[SJP]: Słownik Języka Polskiego PWN. <https://sjp.pwn.pl/>

Soares, C. (2020). Vamos lá falar em... Covidês. As palavras que a pandemia colocou na nossa boca. Visão, 16/05/2020. <https://visao.sapo.pt/atualidade/sociedade/2020-05-16-vamos-la-falar-em-covides-as-palavras-que-a-pandemia-colocou-na-nossa-boca/>

Timóteo, J. (2020). A aldeia portuguesa que se chama Covide e que se tornou num fenómeno este ano! On fm, 30/11/2020. <https://www.onfm.pt/2020/11/30/a-aldeia-portuguesa-que-se-chama-covide-eque-se-tornou-num-fenomeno-este-ano/>

Três Pontos. (2020). Caça ao neologismo nos tempos da pandemia - quem alinha? Três Pontos, 25/03/2020. <https://www.trespontos.pt/post/ca\%C3\%A7a-ao-neologismo-nos-tempos-da-pandemia-quem-alinha>

Vidente Luemba, A. (2020). Descodificando o léxico e a semântica da Covid-19. Jornal de Angola, 26/04/2020, 18-19. <https://imgs.sapo.pt/jornaldeangola/img/1008608020_caderno_fim-de-semana_26.04.2020.pdf>

Villalva, A. (2003). Formação de palavras: composição. In M. H. Mira Mateus et al., Gramática da Língua Portuguesa (7.a edição) (pp. 969-983). Lisboa: Caminho.

[WikiPL]: Wikisłownik. Wolny, wielojęzyczny słownik. <https://pl.wiktionary.org/wiki/Wikis\%C5\%82ownik:Strona_g\%C5\%82\%C3\%B3wna>

[WikiPT]: Wikicionário. O dicionário livre. <https://pt.wiktionary.org/wiki/Wikcion\%C3\%A1rio:P\%C3\%A1gina_principal>

[WSJP]: Żmigrodzki, P. (Ed.). Wielki słownik języka polskiego PAN. <https://wsjp.pl/>

Zdziebłowski, S. (2020). Prof. Bralczyk: mam nadzieję, że wiele słów związanych z epidemią nie zostanie na długo. Nauka w Polsce, 09/06/2020. <https://naukawpolsce.pap.pl/aktualnosci/news,82594,prof-bralczyk -mam-nadzieje-ze-wiele-slow-zwiazanych-z-epidemia-nie-zostanie>

Zimmer, B. (2021). Covid, o neologismo que definiu 2020 (tradução e adaptação anónima). Ciberdúvidas da Língua Portuguesa, 08/01/2021 <https://ciberduvidas.iscte-iul.pt/outros/diversidades/covid-o-neologismo-que-definiu-2020/4352>

Todas as páginas web foram consultadas na primeira metade de fevereiro de 2021. 
